\title{
Trends and variation in mild disability and functional limitations among older adults in Norway, 1986-2008
}

\author{
Joakim O. Moe $\cdot$ Terje P. Hagen
}

Published online: 20 February 2011

(c) The Author(s) 2011. This article is published with open access at Springerlink.com

\begin{abstract}
An increase in the number of older adults may raise the demand for health and care services, whereas decreasing prevalence of disability and functional limitations among them might counteract this demographic effect. However, the trends in health are inconsistent between studies and countries. In this article, we estimated the trends in mild disability and functional limitations among older Norwegians and analyzed whether they differ between socio-demographic groups. Data were obtained from repeated cross-sectional surveys conducted in 1987, 1991, 1995, 2002, 2005, and 2008, in total 4,036 noninstitutionalized persons aged 67 years or older. We analyzed trends using multivariate logistic regression. On average, the age-adjusted trend in functional limitations was $-3.3 \%$ per year, and in disability $3.4 \%$ per year. The risk for functional limitations or disability was elevated for women compared to men, for married compared to nonmarried, and was inversely associated with educational level The trends were significantly weaker with increasing age for disabilities, whereas none of the trends differed significantly between subgroups of sexes, educational level or marital status. Both functional limitations free and disability-free life expectancy appeared to have increased more than total life expectancy at age 67 during this period. The analysis suggests downward trends in the prevalence of mild disability and functional limitations among older Norwegians between 1987 and 2008 and a compression of
\end{abstract}

Communicated by Dorly J. H. Deeg.

J. O. Moe $(\bowtie) \cdot$ T. P. Hagen

Department of Health Management and Health Economics, Institute of Health and Society, University of Oslo, Blindern, P.O. Box 1089, 0317 Oslo, Norway

e-mail: j.o.moe@medisin.uio.no lifetime in such health states. The reduced numbers of older people with disability and functional limitations may have restrained the demand for health and care services caused by the increase in the number of older adults.

Keywords Health trends - Functional limitations · Disability · Aged - Socio-economic inequalities - IADL . Health expectancy

\section{Introduction}

Life expectancy increased substantially during the past century in Norway, as in most other industrialized countries (Oeppen and Vaupel 2002). Improvements in infant and childhood survival contributed most to this increase. After the 1950s, however, the most important factor contributing to the increased life expectancy has been decreasing old age mortality (Christensen et al. 2009). Prolonged life expectancy may be accompanied by expansion (Gruenberg 1977) or compression (Fries 1980) of morbidity and disability at the end of life (Robine and Michel 2004). Decreasing mortality might also be accompanied by less impact and risk of complications of established diseases (Manton 1982). These potential consequences are important for individuals as well as for society and the welfare state. Disability increases the risk of complications of diseases and is associated with greater consumption of health and care services as well as increased mortality (Ostir et al. 1999).

The combination of low fertility and increasing life expectancy leads to an ageing society (Robine and Michel 2004) and has highlighted the need to address the issues relating to health and disability among older adults for decades. Several studies suggest that the proportion of 
older people with functional limitations or mild disability has declined over the past 20-30 years in most industrialized countries (Freedman et al. 2002; Parker et al. 2008; Puts et al. 2008; Sagardui-Villamor et al. 2005; Schoeni et al. 2001; Schoeni et al. 2006; Sulander et al. 2003) and in Norway (Hagen et al. 2002). The results from countries outside the USA are, however, partly contradictory (Parker and Thorslund 2007; Robine and Michel 2004; Zimmer et al. 2002).

The diverging results from European studies are challenging. Most studies are based on two to four measuring points, which make the estimates sensitive to random variations between the repeated cross-sectional surveys (Parker et al. 2008; Schoeni et al. 2001). This article aimed to estimate the trends in the prevalence of functional limitations and mild disability among Norwegian older people from 1986 to 2008 and is based on data from six household surveys. Contrary to most other studies, we also tested the effects of socio-economic and socio-demographic variables according to age and sex groups, educational level and marital status. Based on the observed proportion of older adults with functional limitations and data on the demographic changes over this period, we calculated the changes in the estimated number of persons with functional limitations in the age groups 67-79 years and 80 years and older, and in the total population for the period 1986-2008. Finally, we tested for trends in life expectancy without mild disability (DFLE) and functional limitations (FLFLE).

\section{Materials and methods}

\section{Theory}

The Disablement Process model developed by Verbrugge and Jette (1994) describes how pathology might result in impairment, functional limitation, and eventually disability. Functional limitations are defined as situation-free restrictions in performing physical and mental actions used in daily life. These limitations depend only on the individual's capability. Examples of functional limitations are walking, climbing stairs, and hearing the phone ring. Disability relates to the difficulty in doing activities of daily life that are always performed in a social context. Disabilities emerge when the gap between the capability of the person and the environmental demands becomes too large (Cambois et al. 2008; Ostir et al. 1999). The most frequently studied disabilities are those relevant for personal care (basic activities of daily living, ADL) (Katz et al. 1963), household management (instrumental activities of daily life, IADL) (Lawton and Brody 1969) and paid employment (Verbrugge and Jette 1994). IADL include the ability to use the telephone, shop for personal items, manage one's money, do light housework and prepare one's meals. Verbrugge and Jette also emphasize that other domains of activity are important, for instance the ability to get out of one's home without help or to participate in organizational activities

Both functional limitations and disability might also lead to feedback effects, which may worsen existing pathology or prompt new ones (Ostir et al. 1999; Verbrugge and Jette 1994).

\section{Data source}

We used data from the Surveys of Level of Living (SLL) of 1987, 1991, 1995, and the Surveys of Living Conditions (SLC) of 2002, 2005, and 2008. Statistics Norway (SN) conducted both. The surveys used person samples drawn using a standard two-stage selection scheme. In the first stage, the population was divided into sample areas stratified by the number of inhabitants, industrial structure, and centrality. For each of the strata, one sample area was drawn with a probability proportional to the area's share of inhabitants in the strata. In the second stage, the sample of persons was drawn at random from the sample areas. This made the gross samples nationally representative for the non-institutionalized part of the Norwegian population aged 67 years and older.

The gross samples were self-weighted for all of the study years besides 1987 when the sample was stratified by age with oversampling of those aged 80 and over. The SLC studies had pure cross-sectional design, whereas parts of the samples from the SLL were panel samples; of the net samples in 1991 and 1995, 37\% of persons aged 79 years and younger had also been interviewed in 1987. SN instructed interviewers to primarily attempt to obtain faceto-face interviews until 2002. However, telephone interviews were increasingly used from 1995 and were the preferred interview mode in 2005 and 2008, with allowance for offering face-to-face interviews to older people. Thus in surveys from 1987 to 1995, personal interviews were used predominantly before a decline to the lowest level in 2008 (67-79 years old: 22\%, 80 years and older: $36 \%)$. The SLL were conducted in the periods from January to March in 1987-1995, and the SLC from September to March in 2002-2008. SN later linked educational data to the completed surveys. Period life tables were calculated by $\mathrm{SN}$ and made available by The Human Life-Table Database (2010).

\section{Weighting}

We stratified the net sample by study year and then calibrated the samples with non-scaled weights. These weights were calculated as the share of an age-sex group in the 
population of a study year divided by the corresponding share in the net sample (Thomsen et al. 2006). We used two sets of weights. In the table analysis, we used age standardization so that the net sample for each survey year had the same age-sex distribution as the study population in 2005. In the regression analysis, we used population weights so that the proportions of age-sex groups in the net samples were the same as in the study population of the respective years. We used data from $\mathrm{SN}$ and Norwegian Social Science Data Services (NSD) to calculate the study population as the number of residents in each age-sex group in Norway minus the number of institutionalized individuals. For 1987, 1991 and 2008, there are missing institutional data, and for these years, we estimated the number of institutionalized people in the age-sex groups as a linear trend of proportions of age-sex groups in institutions throughout the other years. The non-weighted net sample of persons aged 67 years and older was 4,036 persons. It was about 3,739 persons after population weighting and 3,729 persons after age standardization with 2005 as the reference year. Table 1 shows the age-sex distributions of the gross sample, non-responders and net sample, and the weighted net samples.

\section{Dependent variables}

We used three functional limitations and four disability items as the dependent variables (Verbrugge and Jette 1994). Two of the disabilities belong to the IADL index (Lawton and Brody 1969). In the 1987 and 1991 surveys, the following functional limitations were assessed with the question "Do you have difficulty with ..." (yes/no): "carrying an object of $5 \mathrm{~kg}$ over a short distance, say $10 \mathrm{~m}$ ?", "going for a five-minute walk at a quick tempo?" and "walking on stairs". These questions were later changed by adding the words "... without resting?" at the end of each question (1995-2008). In 2008, SN added further questions after each that asked the respondent to grade the extent of difficulties. The two IADL functions were assessed with the questions: "Can you without the help of others ...", “... do the grocery shopping?" and "... clean the apartment?". The other two disability items were assessed with the question: "Do you have difficulties, because of health problems or permanent disability ..." "to get out of your home without assistance?" and "to participate in organizational activities?". Until 1995, the last two questions were asked only of those who also indicated they had a permanent disease or disorder. The proportion reporting a permanent disease or disorder varied between 77 and $85 \%$ during the period and there were indications of an upward trend $(P=0.054)$. To make the input filter consistent, we estimated the trend in having both a disability and a disease or disorder, with the net sample as the denominator. The last two questions had an ordinal outcome and we recoded "somewhat difficult", "very difficult" and "not possible" as "difficulty".

We grouped the items into two different nominal dichotomous indexes: one named functional limitation $($ Cronbach alpha $=0.780)$, and one named disability (Cronbach alpha $=0.815)$. We coded them as "failure" if at least one difficulty was in the included items.

Table 1 Age and sex distribution in gross sample, non-response and net samples, and weighted net samples

\begin{tabular}{|c|c|c|c|c|c|c|c|c|c|c|c|c|c|c|}
\hline \multirow[t]{2}{*}{ Survey year } & \multicolumn{2}{|l|}{1987} & \multicolumn{2}{|c|}{1991} & \multicolumn{2}{|c|}{1995} & \multicolumn{2}{|c|}{2002} & \multicolumn{2}{|c|}{2005} & \multicolumn{2}{|l|}{2008} & \multicolumn{2}{|l|}{ Total } \\
\hline & $n$ & $\%$ & $n$ & $\%$ & $n$ & $\%$ & $n$ & $\%$ & $n$ & $\%$ & $n$ & $\%$ & $N$ & $\%$ \\
\hline Gross sample & 1311 & 100 & 884 & 100 & 840 & 100 & 804 & 100 & 764 & 100 & 1523 & 100 & 6126 & 100 \\
\hline $67-79$ & 694 & 100 & 689 & 100 & 635 & 100 & 547 & 100 & 511 & 100 & 1003 & 100 & 4079 & 100 \\
\hline $80+$ & 617 & 100 & 195 & 100 & 205 & 100 & 257 & 100 & 253 & 100 & 520 & 100 & 2047 & 100 \\
\hline Non-response & 372 & 28 & 308 & 35 & 261 & 31 & 297 & 37 & 298 & 39 & 570 & 37 & 2106 & 34 \\
\hline $67-79$ & 176 & 25 & 224 & 33 & 187 & 29 & 184 & 34 & 178 & 35 & 338 & 34 & 1287 & 32 \\
\hline $80+$ & 196 & 32 & 84 & 43 & 74 & 36 & 113 & 44 & 120 & 47 & 232 & 45 & 819 & 40 \\
\hline Net sample & 939 & 72 & 576 & 65 & 579 & 69 & 508 & 63 & 470 & 62 & 964 & 63 & 4036 & 66 \\
\hline $67-79$ & 518 & 75 & 465 & 67 & 448 & 71 & 363 & 66 & 337 & 66 & 671 & 67 & 2802 & 69 \\
\hline $80+$ & 421 & 68 & 111 & 57 & 131 & 64 & 145 & 56 & 133 & 53 & 293 & 56 & 1234 & 60 \\
\hline Net sample, population weighted & 643 & 49 & 576 & 65 & 579 & 69 & 512 & 64 & 468 & 61 & 961 & 63 & 3739 & 61 \\
\hline $67-79$ & 507 & 73 & 447 & 65 & 437 & 69 & 344 & 63 & 316 & 62 & 650 & 65 & 2701 & 66 \\
\hline $80+$ & 136 & 22 & 129 & 66 & 142 & 69 & 168 & 65 & 152 & 60 & 311 & 60 & 1038 & 51 \\
\hline Net sample, age-standardized & 630 & 100 & 576 & 100 & 579 & 100 & 512 & 100 & 468 & 100 & 964 & 100 & 3729 & 100 \\
\hline $67-79$ & 425 & 68 & 389 & 68 & 391 & 68 & 334 & 65 & 316 & 68 & 650 & 67 & 2505 & 67 \\
\hline $80+$ & 205 & 32 & 187 & 32 & 188 & 32 & 178 & 35 & 152 & 32 & 314 & 33 & 1224 & 33 \\
\hline
\end{tabular}


Independent variables

The independent variables were survey year standardized as the year of the closest New Years Eve, sex, age at 31 December in the standardized survey year, marital status or cohabitating, and educational level.

The level of education was classified as lower level (up to 9 years), high school level (10-13 years), or university or college (14 years or more).

\section{Missing data}

The proportion of non-responders increased with years. The average non-response share was $34 \%$, and increased from $28 \%$ (1986) to $37 \%$ (2008). Within the age group 67-79 years, the average non-response share was $32 \%$, which increased from 25 to $34 \%$. Persons 80 years and older had the largest non-response rate, with an average share of $40 \%$, which increased from 32 to $45 \%$. We sought to reduce the non-response selection bias by using weights (Thomsen et al. 2006).

The maximum proportion of items missing was $5.9 \%$ in the disability variable in 1995 , but this decreased to $2.7 \%$ when all years were considered simultaneously. Besides disability in 1995, none of the study years had a proportion of missing items greater than 5\%. Cases with missing items were excluded from the analysis.

\section{Statistical analysis}

First, we tested whether there was any trend in the prevalence of any items of functional limitations or disability using table analysis on age-standardized data. In the initial analysis of the composite indexes, we estimated the agestandardized cumulative odds ratios (ORs) and absolute risk differences in functional limitations and disability between the periods 1986-1995 and 2002-2008. The linear trends in both indexes were then estimated as the average age-adjusted relative change in odds per year throughout the period (OR) using multivariate logistic regression analysis on population-weighted data. We adjusted the trends for compositional factors besides age, and thus estimated the effects of sex, educational level, and marriage or cohabitation. Educational level was coded as a dummy variable with the lower level as the reference group.

Disparities in trends were studied by multivariate logistic regression, where we estimated the age-adjusted trends stratified by the compositional groups. We tested for disparities in trends between these subgroups by testing for significant improvement in likelihood ratio when allowing for interactions between group and survey year on the nonstratified dataset.
Departures from the linear predicted trend were tested by introducing a dummy for survey year one by one. We controlled for selection bias by means of two sensitivity analysis. First, we estimated the trends on the assumption that all non-responders had disability and functional limitations. In the second analysis, we expanded the gross sample from the first analysis with a proportionate share of the institutionalized population with the same assumption as above. In order to keep the power of the analysis stable, we weighted this new sample to equal the gross sample in numbers above and below 80 years old. Trends from the sensitivity analysis were adjusted for age below or above 80 years.

We estimated the number of older adults with functional limitations throughout the period by combining the past demographic development with the observed proportion with functional limitations in the population-weighted net sample stratified by age above and below 80 years old.

Finally, we calculated health expectancies by Sullivan's method for each period using abridged life tables gender and stratified in two age groups separated at the age of 80 (Jagger et al. 2006; Sullivan 1971). Sex-specific health expectancies at the age of 67 were computed by applying the age- and sex-specific cross-sectional prevalence rates of functional limitations and disabilities to the corresponding age- and sex-specific person-years derived from a period life table. As proposed by Jagger et al. (2006), we assumed the institutionalized population to be functionally limited and disabled. We also assumed the random variation arising from the mortality rates to be negligible, leaving the surveys to be the only source of random variation. We used weighted least square regression to estimate the average yearly change in life and health expectancies and tested for linear trends, using weights equal to the inverse variance of the estimate of each indicator at each year.

We regarded two-sided $P$ values $<0.05$ as statistically significant and used the likelihood-ratio test to estimate $P$ values in regression analysis. PASW Statistic 18.0 (SPSS Inc., 2009) was used for data analysis.

\section{Results}

Table 2 describes the population-weighted net sample in terms of age, sex, level of education and marital status. Age composition reflects the demographic development arising from smaller cohorts throughout the 1930s, and increasing life expectancy. This has led to an increase in the population of older people throughout the period so that the median age increased from 74 to 76 years. The median level of education also increased during the period from equivalent to lower level education in 1986 to high school level in 2008. 
Table 2 Description of study samples across survey years (population weighted), $N=3739$

\begin{tabular}{|c|c|c|c|c|c|c|c|c|c|c|}
\hline \multicolumn{2}{|c|}{ Independent variables } & \multirow{2}{*}{$\begin{array}{l}1987 \\
(\%)\end{array}$} & \multirow{2}{*}{$\begin{array}{l}\begin{array}{l}1991 \\
(\%)\end{array} \\
1990\end{array}$} & \multirow{2}{*}{$\begin{array}{l}\begin{array}{l}1995 \\
(\%)\end{array} \\
1994\end{array}$} & \multirow{2}{*}{$\begin{array}{l}2002 \\
(\%)\end{array}$} & \multirow{2}{*}{$\begin{array}{l}\begin{array}{l}2005 \\
(\%)\end{array} \\
2005\end{array}$} & \multirow{2}{*}{$\begin{array}{l}\begin{array}{l}2008 \\
(\%)\end{array} \\
2008\end{array}$} & \multirow{2}{*}{$\begin{array}{l}\begin{array}{l}\text { Total } \\
(N)\end{array} \\
3739\end{array}$} & \multirow{2}{*}{$\begin{array}{l}\begin{array}{l}\text { Missing } \\
(n)\end{array} \\
0\end{array}$} & \multirow{2}{*}{$\begin{array}{l}\text { Trend } \\
\text { test }(P)\end{array}$} \\
\hline & Standardized survey year & & & & & & & & & \\
\hline \multirow[t]{2}{*}{ Sex } & Female & 58 & 58 & 58 & 58 & 57 & 57 & & & 0.455 \\
\hline & Valid $N$ & 643 & 576 & 579 & 512 & 468 & 961 & 3739 & 0 & \\
\hline \multirow[t]{5}{*}{ Age group } & $67-74$ & 55 & 54 & 51 & 42 & 43 & 45 & & & \\
\hline & $75-79$ & 24 & 24 & 24 & 25 & 24 & 23 & & & \\
\hline & $80-84$ & 14 & 14 & 16 & 20 & 20 & 18 & & & \\
\hline & $85+$ & 7 & 8 & 9 & 13 & 13 & 15 & & & \\
\hline & Valid $N$ & 643 & 576 & 578 & 511 & 468 & 961 & 3739 & 0 & $<0.001$ \\
\hline \multirow[t]{2}{*}{ Marital status } & Married or cohabitating & 56 & 53 & 57 & 55 & 55 & 59 & & & \\
\hline & Valid $N$ & 644 & 560 & 577 & 512 & 468 & 961 & 3722 & 18 & 0.062 \\
\hline \multirow[t]{4}{*}{ Educational level } & Lower level ( $<9$ years) & 76 & 57 & 51 & 42 & 43 & 37 & & & \\
\hline & High school level (10-13 years) & 19 & 40 & 46 & 44 & 42 & 44 & & & \\
\hline & University/college ( $>14$ years) & 5 & 4 & 3 & 14 & 14 & 19 & 3683 & 57 & $<0.001$ \\
\hline & Valid $N$ & 639 & 567 & 574 & 504 & 464 & 935 & & & \\
\hline
\end{tabular}

Figures 1 and 2 show the age-standardized changes in the dependent variables. All items and indexes had highly significant downward trends $(P<0.001)$. Between 1986-1994 and 2002-2008, the odds of having functional limitations decreased with OR of 0.60 (95\% confidence interval (CI), 0.53-0.69). The decrease in disability was very similar with OR of 0.60 (95\% CI, 0.52-0.69). The risk difference between these periods was 12 percentage points (95\% CI, 9-15\%) for both indexes (analysis not shown in table).

Table 3 shows the results of the two logistic regression analyses on populated-weighted samples. The first analysis regressed the functional limitations and the second disability. We started by estimating the age-adjusted relative change in odds per year (OR), and then the effects of survey year, yearly ageing, sex, marriage or cohabitation, and educational level combined.

The age-adjusted odds for functional limitations declined by about $3.3 \%$ per year $(P<0.001)$, and for disability by $3.4 \%$ per year $(P<0.001)$. Both trends were slightly weakened when adjusting for compositional factors. The multivariate analysis showed substantial and highly significant relative differences in prevalence between sexes and different educational level. Education from university or college was associated with a reduction of the odds for both functional limitations and disabilities by $40 \%(P<0.001)$ compared to those with lower level of education, whereas those with only high school level education had reductions of $27 \%(P<0.001)$ and $19 \%$ $(P=0.009)$ respectively. Being female doubled the odds
Fig. 1 Percentage with functional limitations, agestandardized $(N=3,729)$

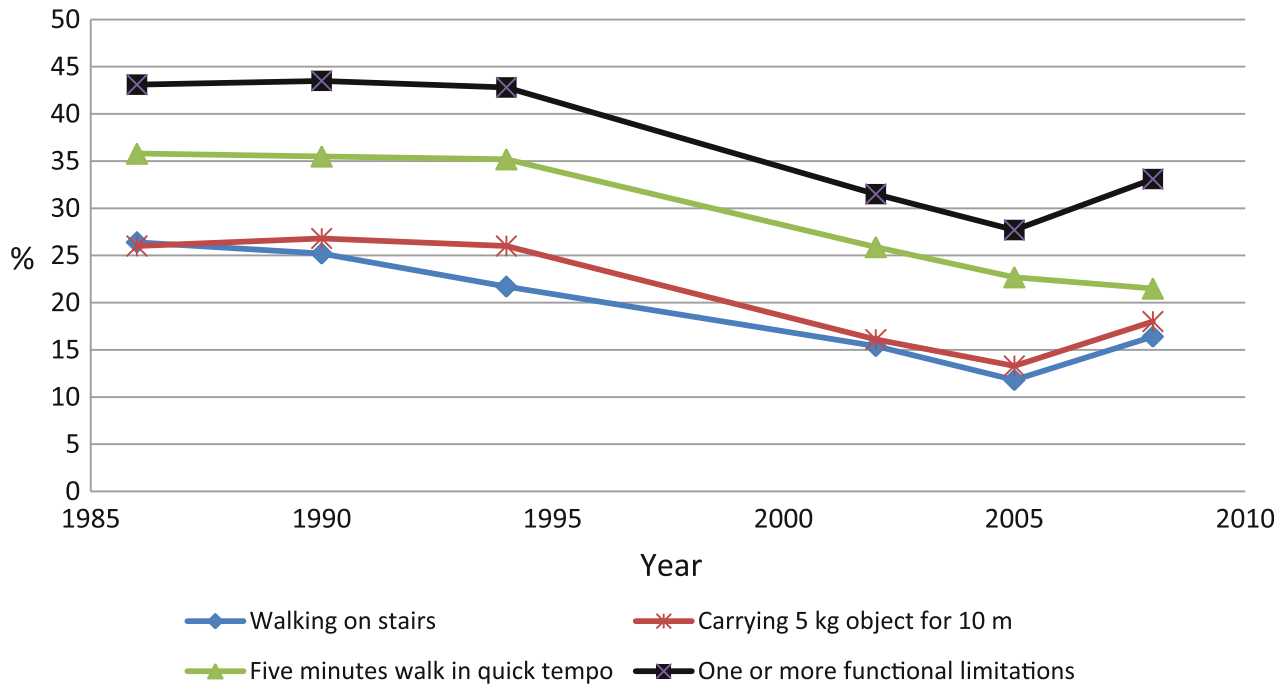


Fig. 2 Percentage with disabilities, age-standardized $(N=3,729)$

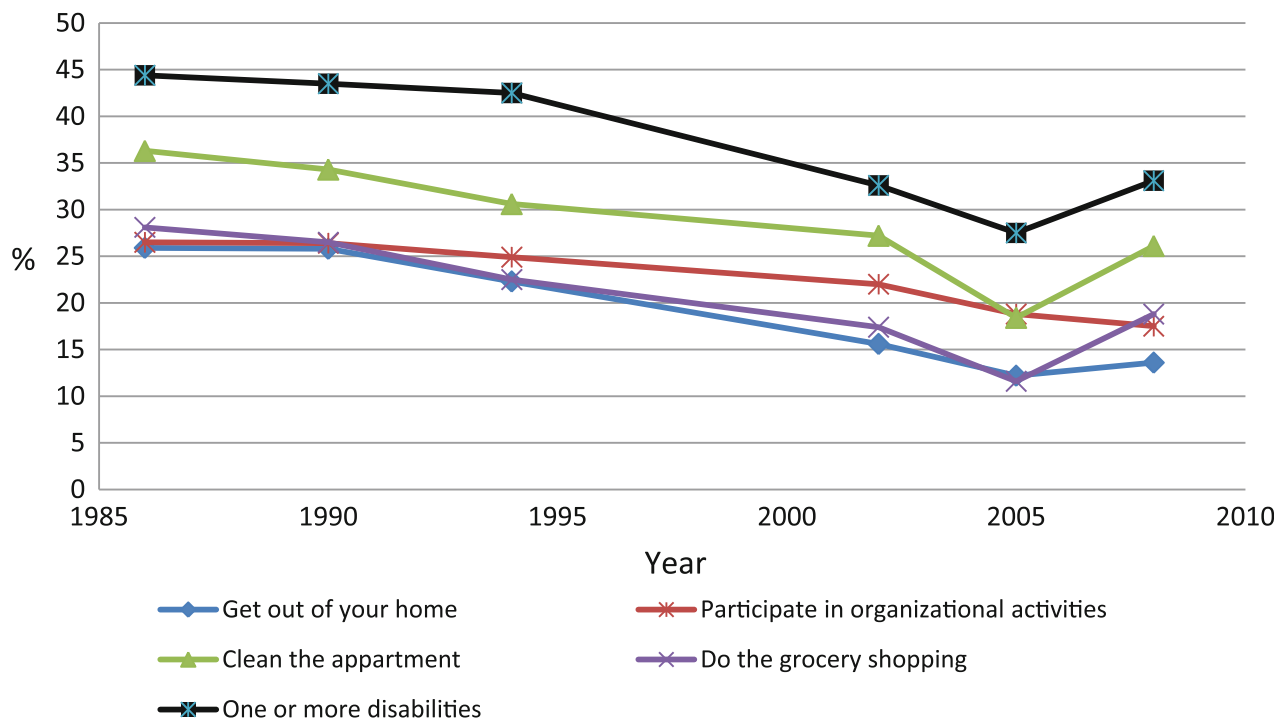

Table 3 Estimated linear trends, effects of sex, age, marital status, and educational level

\begin{tabular}{|c|c|c|c|c|}
\hline & \multicolumn{2}{|l|}{ Functional limitations } & \multicolumn{2}{|l|}{ Disabilities } \\
\hline & Age adjusted & Full model & Age adjusted & Full model \\
\hline Survey year & $0.967(0.959-0.976)^{* * *}$ & $0.974(0.965-0.983)^{* * *}$ & $0.966(0.957-0.974) * * *$ & $0.972(0.963-0.981)^{* * *}$ \\
\hline Age & $1.11(1.09-1.12)^{* * *}$ & $1.10(1.08-1.11)^{* * *}$ & $1.12(1.10-1.13) * * *$ & $1.11(1.09-1.12)^{* * *}$ \\
\hline Sex (female) & & $1.94(1.65-2.27) * * *$ & & $1.51(1.28-1.77)^{* * *}$ \\
\hline Married or cohabitating & & $0.81(0.69-0.95) * *$ & & $0.85(0.72-1.00)^{*}$ \\
\hline \multicolumn{5}{|l|}{ Educational level } \\
\hline Low & & 1.00 & & 1.00 \\
\hline High school & & $0.73(0.62-0.85)^{* * *}$ & & $0.81(0.69-0.95)^{* *}$ \\
\hline University/College & & $0.60(0.45-0.79)^{* * *}$ & & $0.61(0.46-0.81)^{* * *}$ \\
\hline Valid $N$ (missing) & $3643(96)$ & & 3570 (169) & \\
\hline
\end{tabular}

Results from multivariate logistic regression $(\mathrm{OR}(95 \% \mathrm{CI}))$; population-weighted sample $(N=3,739)$

$* P<0.050$; ** $P<0.010$; *** $P<0.001$

for functional limitations $(P<0.001)$ and increased the odds for disability by $50 \%(P<0.001)$. Being married or cohabitating reduced the odds for functional limitations by $20 \%(P=0.008)$ whereas the reduction in disability was $15 \%(P=0.045)$.

Table 4 shows trends for different subgroups assessed in the stratified regression analysis of the effect of time on the dependent variables.

The trends were reduced by adjusting for compositional factors in all strata but according to educational level. The group with the highest educational level had the weakest and non-significant trends. The trends appeared to be stronger in women than in men, although not significantly. The tendency to weaker trends with increasing age for disabilities was significant $(P=0.045)$. The observed prevalence rates departed from what was predicted by linear trend in 1995, 2002, 2005, and 2008 for functional limitations and in 2005 and 2008 for disability. The survey of 2008 differed the most from the linear prediction with $\mathrm{OR}=1.40(P=0.006)$ for functional limitations and OR $=1.39(P=0.006)$ for disability, followed by the 2005 data with $\mathrm{OR}=0.73 \quad(P=0.011)$ and 0.70 $(P=0.005)$ respectively.

In the sensitivity analysis, we assumed all nonresponders had functional limitations and disability. The trends remained highly significant, albeit weaker, with trends in functional limitations $(\mathrm{OR}=0.991 ; 95 \% \mathrm{CI}$, $0.985-0.997 ; P=0.003)$ and in disability $(\mathrm{OR}=0.989$; 95\% CI, 0.983-0.995; $P<0.001)$. Although the interaction term did not reveal significant disparities in trends between those younger and those older than 80 years $(P=0.395$ and $P=0.244$ ), the trends were not significant in the older group when tested separately $(P=0.324$ and $P=0.331)$. The results were roughly the same even if all missing items of the indexes were given the value of functional limitation or disability. After adjustment for trends in institutional 
Table 4 Stratified analysis, linear trend for functional limitations and disability

\begin{tabular}{|c|c|c|c|c|}
\hline & \multicolumn{2}{|l|}{ Functional limitations } & \multicolumn{2}{|l|}{ Disabilities } \\
\hline & Age-adjusted & Full model $^{\mathrm{a}}$ & Age-adjusted & Full model ${ }^{\mathrm{a}}$ \\
\hline \multicolumn{5}{|l|}{ Sex } \\
\hline Female & $0.964(0.954-0.975)^{* * *}$ & $0.972(0.961-0.984)^{* * *}$ & $0.963(0.952-0.973)^{* * *}$ & $0.967(0.956-0.979) * * *$ \\
\hline Male & $0.972(0.959-0.986)^{* * *}$ & $0.978(0.963-0.992)^{* *}$ & $0.972(0.958-0.986)^{* * *}$ & $0.979(0.964-0.993) * *$ \\
\hline Trend $*$ sex & & $P=0.625$ & & $P=0.280$ \\
\hline \multicolumn{5}{|l|}{ Age } \\
\hline $67-74$ & $0.963(0.951-0.976)^{* * *}$ & $0.972(0.959-0.986)^{* * *}$ & $0.960(0.947-0.972)^{* * *}$ & $0.967(0.954-0.981)^{* * *}$ \\
\hline $75-79$ & $0.970(0.954-0.986)^{* * *}$ & $0.976(0.958-0.994)^{* *}$ & $0.967(0.950-0.983)^{* * *}$ & $0.975(0.958-0.993)^{* *}$ \\
\hline $80-84$ & $0.969(0.950-0.989)^{* *}$ & $0.974(0.953-0.994) * *$ & $0.977(0.957-0.996)^{*}$ & $0.981(0.961-1.001)$ \\
\hline $85+$ & $0.982(0.956-1.008)$ & $0.987(0.960-1.015)$ & $0.976(0.950-1.002)$ & $0.977(0.951-1.005)$ \\
\hline Trend $*$ agegroup & & $P=0.104$ & & $P=0.045$ \\
\hline \multicolumn{5}{|l|}{ Educ. level (years) } \\
\hline Lower school ( $<9$ years) & $0.976(0.964-0.987)^{* * *}$ & $0.976(0.964-0.987)^{* * *}$ & $0.972(0.960-0.983)^{* * *}$ & $0.972(0.961-0.984) * * *$ \\
\hline High school (10-12 years) & $0.973(0.958-0.988)^{* * *}$ & $0.972(0.957-0.988)^{* * *}$ & $0.970(0.955-0.985)^{* * *}$ & $0.970(0.955-0.985)^{* * *}$ \\
\hline University or college ( $>13$ years) & $0.980(0.945-1.016)$ & $0.976(0.940-1.013)$ & $0.987(0.950-1.025)$ & $0.983(0.945-1.023)$ \\
\hline Trend $*$ educ. level dummy & & $P=0.895$ & & $P=0.666$ \\
\hline \multicolumn{5}{|l|}{ Marital status } \\
\hline Married or cohabitating & $0.968(0.957-0.980)^{* * *}$ & $0.972(0.959-0.984)^{* * *}$ & $0.969(0.958-0.981)^{* * *}$ & $0.974(0.962-0.986)^{* * *}$ \\
\hline Not married or cohabitating & $0.970(0.957-0.982)^{* * *}$ & $0.978(0.965-0.991)^{* *}$ & $0.964(0.952-0.977)^{* * *}$ & $0.969(0.956-0.982) * * *$ \\
\hline Trend $*$ marriage or cohabitating & & $P=0.765$ & & $P=0.508$ \\
\hline
\end{tabular}

Multivariate logistic regression analysis. $P$ values are the significance-levels of the interaction terms between strata and survey years on the nonstratified dataset

* $P<0.05, * * P<0.01$, *** $P<0.001$

a Trends from the full model are adjusted for sex, age, education level, and marital status

care in the second sensitivity analysis, the trends were still significant in the total sample for both indexes $(\mathrm{OR}=0.989, \quad P<0.001$ and $\mathrm{OR}=0.987, \quad P<0.001$ respectively). However, stratifying by age above and below 80 years old gave significant trends in the older group only at $10 \%$-level $(P=0.100$ and $P=0.099)$.

Compression or expansion of morbidity?

Life expectancy at age $67\left(\mathrm{e}_{67}\right)$ increased substantially from the mid 1990s after a period of stagnation (Table 5). The total increases for men and women between 1986 and 2008 were 2.8 and 2.0 years, respectively. However, expected lifetime without functional limitations $\left(\mathrm{FLFLE}_{67}\right)$ or disabilities $\left(\right.$ DFLE $\left._{67}\right)$ increased more in both sexes. This resulted in a substantial increase in the proportion of expected lifetime without such health problems, among men this proportion increased from 67 to $74 \%$ in FLFLE 67 and 62 to $70 \%$ in DFLE $_{67}$, and among women from 45 to $54 \%$ in FLFLE $_{67}$ and from 47 to $54 \%$ in DFLE $_{67}$. The yearly changes in both FLFLE $_{67}$ and DFLE $_{67}$ were greater than the life expectancy gain, suggesting an absolute compression of functional limitations and disabilities.
Furthermore, the proportion of remaining life in good health also increased, indicating a relative compression.

The effect in a demographic perspective

The older adult population increased throughout the study period due to an $50 \%$ increase in the older age group ( $>80$ years). In contrast, the population between 67 and 79 years old declined by $9 \%$. Figure $3 \mathrm{a}$ and $\mathrm{b}$ show the results of combining this demographic change and the observed proportion with functional limitations throughout this period to give the estimated numbers of older adults with functional disability.

The number of persons aged 67-79 years decreased during the period. The number reporting functional limitations would thus have decreased by about $11,600(8 \%$ reduction) if the prevalence of functional limitations had remained at the 1986 level (34\%) throughout the period. However, the prevalence decreased by $32 \%$ until 2008, which led to a further reduction in the number of people with functional limitations by about 42,700 . In total, we estimate about 54,300 fewer people ( $37 \%$ reduction) in this 
Table 5 Life expectancy at age $67\left(\mathrm{e}_{67}\right)$ in Norway 1986-2008, expected lifetime without functional limitations (FLFLE 67 ) and mild disabilities $\left(\mathrm{DFLE}_{67}\right)$, and proportion of expected lifetime without functional limitations and disabilities

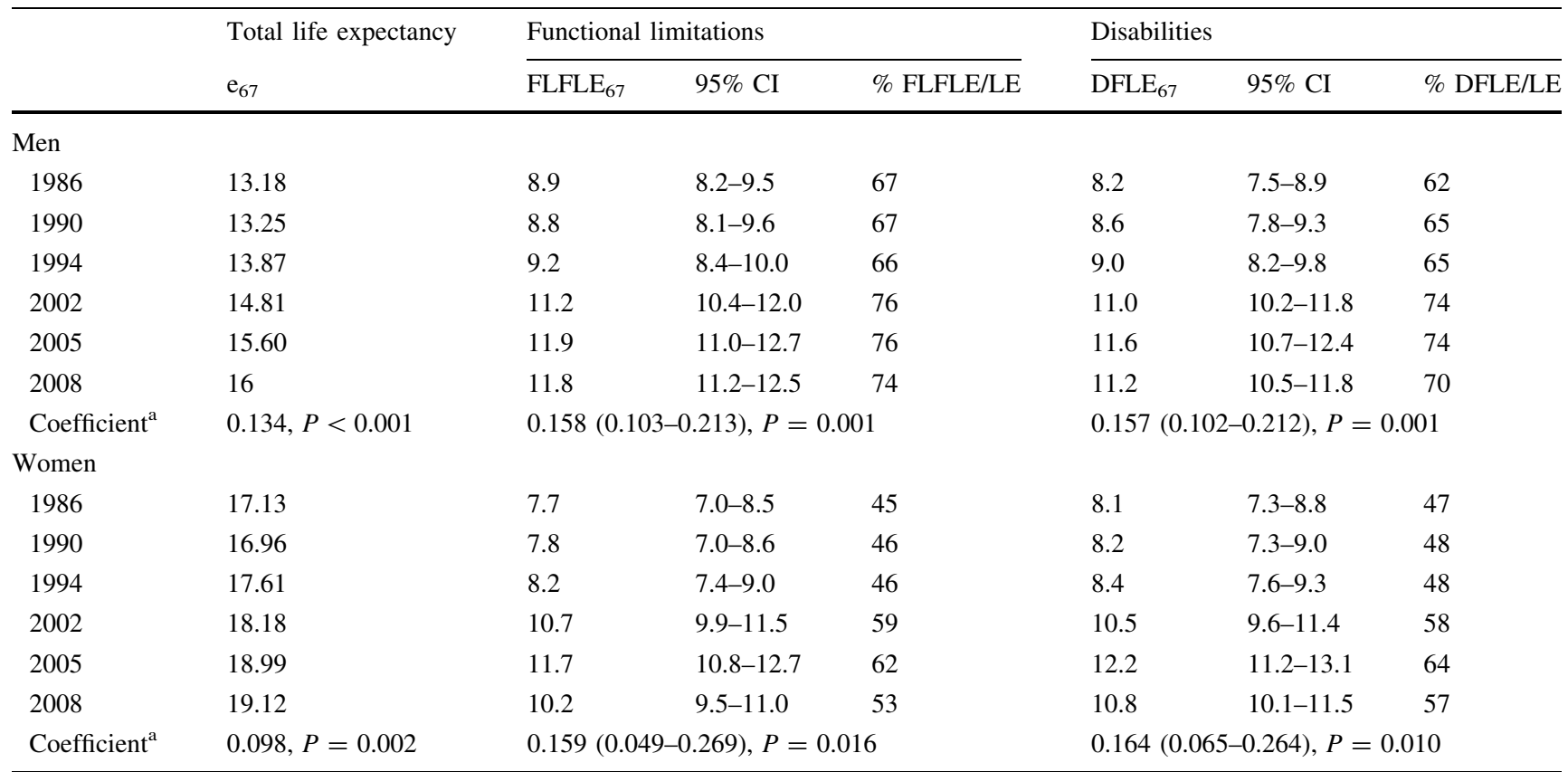

The institutionalized populations are assumed to have both functional limitations and disability. We used weighted least square regression to test for trends in health expectancies and estimate mean changes by year in healthy expectancies

${ }^{a}$ Mean changes by year in health expectancies

age group reporting functional limitations in 2008 compared to 1986.

The number of people older than 80 years increased throughout the period. The number reporting functional limitations would thus have increased by about 45,500 ( $51 \%$ increase), if the proportion with functional limitations had remained at the 1986 level $(62 \%)$ throughout the period. The $13 \%$ reduction in prevalence, to $54 \%$, until 2008 reduced the number with functional limitations by about 17,000 people (19\% reduction). Thus, the reduced prevalence partly counteracted the effect of the demographic changes in this age group so that the total increase in the number of people aged more than 80 years with functional limitations was only 28,400 people (32\% increase).

When the data from both age groups were analyzed together, the demographic changes would, if uncompensated, have added about 33,800 persons with functional limitations throughout this period (14\% increase). However, a $30 \%$ decrease in prevalence resulted in 59,800 fewer people with functional limitations compared with the situation where the prevalence did not change throughout the years. Based on these numbers, we estimated a reduction in the numbers of non-institutionalized older people 67 years and older with functional limitations of 25,900 people (11\% reduction). The estimated prevalence of older people reporting functional limitations in 2008 was $34 \%$ (209,400 people).

Although the numbers of institutionalized older people were relatively stable as can be seen in Figs $3 a$ and b, the proportions of institutionalized people per age group have decreased from about 3 to $2 \%$ among those aged $67-79$ years, and from 23 to $15 \%$ among the oldest old ${ }^{1}$

\section{Discussion}

Our analysis suggests significant and substantial declining trends for both functional limitations and disability over recent decades. The respective average age-adjusted annual changes were 3.3 and $3.4 \%$. Comparing trends between studies and countries is difficult partly because of different study design, time period, age groups, measurement methods, and non-response rates (Freedman et al. 2004; Rodgers and Miller 1997). Our estimates of the trends in Norway are in the upper range of previously estimated trends elsewhere. For Norway Hagen et al. (2002) found a weaker, but significant trend of $-1.3 \%$ by analyzing a slightly different mix of disabilities over the timeframe

\footnotetext{
${ }^{1}$ Estimates based on data from the Regional Database of the NSD and SN.
} 
Fig. 3 Number of older adults in institutions and estimated numbers with and without functional limitations. The dotted lines depict the number that would have reported functional limitations if the proportion with such limitations remained constant at 1986 level throughout the period. a Age $67-79$ years. b Age 80 years and older
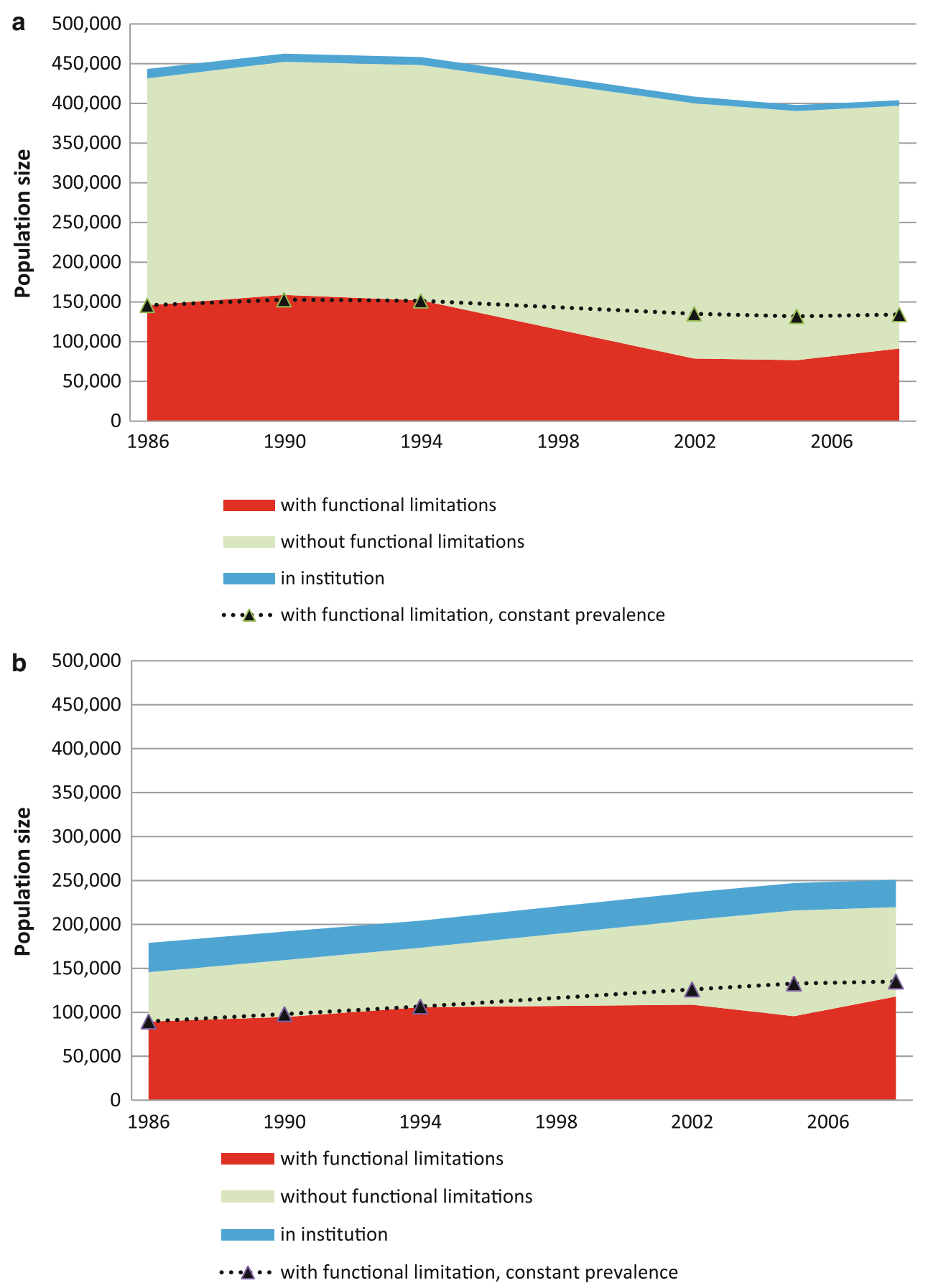

1985-1998; this estimate was not age adjusted. In their recent review, Christensen et al. (2009) summarized results from international studies and reported that the age-adjusted trends in functional limitations during the 1980s and 1990 s varied between $-4.86 \%$ and $0.17 \%$. Freedman et al. report US trends in IADL disability between -2.74 and $-0.40 \%$ for the same period (Freedman et al. 2002). However, the proportion with functional limitations or disability in Taiwan increased throughout the 1990s (Zimmer et al. 2002), and a similar trend was seen in the Swedish population of persons aged 77 years and older
(Parker et al. 2005). Robine and Michel (2004) argued that the differences in trends between countries should be considered in the light of each country's different progress in epidemiological and demographic transitions.

The downward trends were not persistent over time but were concentrated in the latter half of the 1990s. This pattern is consistent for all items of functional limitations and disability (Figs 1, 2). The observed shapes of the prevalence patterns are supported by prevalence data on some of the items also surveyed in the SLC conducted by $\mathrm{SN}$ in 1998 (data not shown here). The trends seem to have 
levelled off after 2002 or to have increased slightly between 2005 and 2008, where we consequently found the largest departures from what was predicted by the linear trend. The fluctuations in prevalence rate between surveys might also result from random variation in survey response rate as well as undetected systematic methodological differences (Parker et al. 2008). We suspect the variations at the end of this period to be related to differences in methods, but SN has been unable to identify a methodological reason. One change between these surveys is the question introduced subsequent to the functional limitations items in the 2008 survey asking the respondents to grade the extent of difficulties. However, although no such additional grading question was introduced subsequent to the disability items, the prevalence pattern of disabilities was similar to that of functional limitations. This suggests that the upswing in prevalence of functional limitations in 2008 is not related to this methodological change. We believe that the sum of the 2002-2008 data provides a reasonably good estimate of the prevalence in these years, and we therefore believe that any potential method-related effects in some of the last three survey years had a negligible effect on these trends. The strong downward trend in the late 1990s might partly explain why our trend estimate is stronger than that in the previous analysis of Norwegian data in 1985-1998 (Hagen et al. 2002). Few studies estimate disability trends using more than two to four measuring points. However, in both the US and Sweden, trends have varied in strength and started to decline a few years before those in Norway (Freedman and Martin 1998; Parker et al. 2008).

Increasing age is the strongest predictor of functional limitations or disability. The subgroup analysis suggested a slightly weaker trend with increasing age, which was significant for disability and significantat at $10 \%$ level for functional limitation (Table 4). This agrees with Finnish data from the 1980s and 1990s (Sulander et al. 2003) and with a previous analysis in Norway (Hagen et al. 2002). The downward trend in US data has been persistent across all age groups (Schoeni et al. 2001). However, Parker et al. presented evidence of a stronger downward trend for older age groups in Sweden (Parker et al. 2008).

Next to age, lower educational level was the strongest predictor of functional limitations or disability. This educational effect persisted throughout the years. The stratified analysis suggested that the trend was weakest in the group with the highest educational level, but this was not significant when all groups were analyzed together. This group was small and this gives wide CIs. Few studies have tested statistically the educational differences in these trends, and the results are mixed. Disparities according to educational levels increased in the US between 1982 and 1996 (Crimmins and Saito 2001; Schoeni et al. 2001) and in Spain between 1986 and 1999 (Sagardui-Villamor et al. 2005), whereas there were no significant trend disparities in Japan between 1993 and 2002 (Schoeni et al. 2006).

Both in the non-stratified sample as well as in all the compositional group strata except by education, adding compositional factors weakened the trend (Tables 3, 4). This suggests that the increase in the proportion of older adults with a higher educational level throughout the period might have contributed to the reduction in the proportion of disabled older people in Norway. Furthermore, it is in line with the results from others (Freedman and Martin 1999), and with the known educational association with morbidity and mortality (Batljan et al. 2009; Cutler and Lleras-Muney 2006; Rostad et al. 2009; Van Oort et al. 2005).

We found that women reported more functional limitations or disability even after adjusting for age, marital status, and educational level. This phenomenon was reported earlier in other industrialized countries (Arber and Ginn 1993; Freedman et al. 2002; Sulander et al. 2003). The reasons for this sex difference are likely complex. In addition to biological causes, differences might reflect differences in the acquired risks of illness and injury, psychosocial aspects of symptoms and care, health reporting behavior and prior health care (Verbrugge 1985). The stratified analysis suggested slightly stronger trends among women, but they did not differ significantly from trends among men. US data suggest a similar reduction in disparities throughout the $1990 \mathrm{~s}$ (Freedman et al. 2002). In contrast, Finnish data showed a possible stronger downward trend among men than women from the 1980s to 1990s (Sulander et al. 2003).

We found indications of compression of lifetime with both functional limitations and disabilities among those 67 years and older. The compression seemed to be both relative and absolute. Thus, the gain in life expectancy at age 67 has been translated into mainly healthy years. Internationally, trends in health expectancies are diverging (Christensen et al. 2009). Several one-country studies suggest larger improvements in disability-free life expectancy than in life expectancy (Christensen et al. 2009; Doblhammer and Kytir 2001; Sagardui-Villamor et al. 2005; Van Oyen et al. 2008), although French data suggest stable health expectancies for moderate levels of disability (Cambois et al. 2008). As health expectancy is a composite measure including both mortality and morbidity trends, interpreting differences in trends requires country-specific knowledge of both trends (Robine and Michel 2004). The composition of health expectancy by prevalence of disability (stock data) and mortality (flow data) makes it vulnerable to bias when there are sudden changes in the equilibrium between incidence, recovery, and mortality associated with the specific health domain (Barendregt et al. 1994; Cambois et al. 2008). However, Mathers and 
Robine (1997) concluded that it provides a good estimate of the true period value if there are smooth and relatively regular changes over the long term.

We note some limitations of this study. Firstly, measuring functional ability among older adults is challenging and there is no aggregated measure that covers all relevant aspects of this dimension. We focused on functional limitations and mild disability. The SLL and SLC do not offer consistent data on more serious disabilities, such as those affecting ADL (Katz et al. 1963) or cognitive failure. ADL functions might be important because they are probably more valid expressions of the demand for health care.

Secondly, self-reported health data are cheaper and easier to obtain from a large sample and are less prone to non-response than surveys based on observational data (Kempen et al. 1996). However, self-reported data on ADL functions are correlated weakly with parallel observational data from physical function tests (Kempen et al. 1996); they might be affected by systematic measurement errors because the probability of reporting a health problem can be affected by sex, age or educational level (Parker et al. 2008), depression, weak self-esteem or low self-perception of physical competence (Kempen et al. 1996). There might also have been a temporal trend in the propensity to consider oneself as disabled, i.e., the traditional gender gap in expectations and requirements of IADL domains might have changed as younger cohorts of men are gradually becoming more competent in these areas (Freedman and Martin 1998; Parker and Thorslund 2007; Verbrugge and Jette (1994).

A mode effect of the increase in the proportion of telephone interviews might yield a biased trend estimate (Bowling 2005; Freedman et al. 2002; Herzog and Rodgers 1988; Rodgers and Miller 1997; Wolf et al. 2005). The extent of such differential response bias is difficult to assess, as the mode of the interview might itself be a consequence of health status (Herzog et al. 1983; Rodgers and Miller 1997). Based on observational cross-sectional data, Rodgers and Miller (1997) found significantly higher risk of disabilities and functional limitations among older people interviewed face-to-face compared to those interviewed by telephone. However, the effect was close to zero and non-significant after taking account of individual demographic and health characteristics. Others have come to similar results (Herzog and Rodgers 1988; Herzog et al. 1983; Wolf et al. 2005). We do not know of published experimental evidence on differential response bias by mode in self-reports of functional limitations or disability. A randomized trial on mode effect on reports of cognitive functioning found no such effects (Herzog et al. 1999), and according to Wolf et al (2005), the same trial did not reveal mode effects on disability measures either. Although these findings might not be applicable to a Norwegian setting, and we cannot exclude that a mode effect changes by time, we believe the extent of a possible differential response bias to be minor compared to the changes in capability over time.

Thirdly, there were small differences in the distribution of men and women and age groups between the nonresponders and responders. However, health surveys among older people may include some selection bias because of the higher probability of non-response in those with poor health and disability. This leads to a possible underestimated prevalence in any given year. We sought to reduce the non-response selection bias using weights (Thomsen et al. 2006). Trend estimates might be valid despite selection bias in prevalence, as long as the degree and direction of selection bias does not change over time. Use of weights does not affect such non-response bias in trend estimates. However, the sensitivity analysis showed that the trend was downward even if all the non-responders had had functional limitations and disability, although not significantly among those above 80 .

Fourth, and closely related, the threshold for access to institutional care has increased. This might have led to an increasing burden of care among the institutionalized population (Waaler 2005) as well as among home care users (Daatland 1997). The development has partly been compensated by the increased use of homed based community services including assisted living housing, which in 2008 served three-quarters of all older people demanding care services (Statistics Norway 2010). As SN does not define these community services as institutions, their users have been eligible to the surveys used in our study. This trend would have contributed to increasing levels of frail older people, and thus prevalence of disabilities and functional limitations among the non-institutionalized population during the period. This development might partly explain the increase in non-responders, especially among the oldest old. It also makes the assumption in the sensitivity analysis that all the non-responders" had functional limitations and disabilities in this age group more likely. However, as shown by our second sensitivity analysis this cannot explain the overall decrease in prevalence of disability or functional limitations in our study.

Fifth, we estimated the trend in having both a disability and a disease or disorder, with the net sample as the denominator. This might have led to underestimation of disability prevalence at any given time. However, as the proportion reporting a permanent disease or disorder might have increased slightly during the period, the effect on the trend is more uncertain and in our view likely to be negligible.

Finally, we mention two methodological factors of uncertain significance: First, SN did not use interviews by proxy in the SLL or SLC. Use of proxy interviews reduces 
the non-response rate but might be associated with information bias (Ostir et al. 1999; Rodgers and Miller 1997). Second, one third of each sample from the SLL (1987-1995) were panel samples, whereas the SLC studies were of pure cross-sectional design. This has not been taken into account in our analysis and led to a slight overestimation of the variance in the data from these years.

\section{Conclusions}

The analysis supports the idea that today's older people are, in some respects, fitter than the same age group 20 years ago. However, the trends might have levelled off after 2002. The improvement in physical health may have overcompensated for the increase in the number of older people with functional limitations because of the demographic changes. Furthermore, we find support of compression of functional limitations and mild disability during this period.

Identifying the causes behind these trends is beyond the scope of this article. Previous studies have suggested cohort effects, prevention effects, development and use of assistive technology (Freedman et al. 2006), and better medical treatment options as possible explanations. However, the latter may also lead to increased morbidity if it leads to more people rescued from fatal diseases than cured of chronic conditions. Improvement of contextual factors both in the home and in public spaces might have contributed to reducing disability (Parker and Thorslund 2007). Given the known educational gradients in health, increases in the number of better-educated old people are also likely to have contributed to these trends (Crimmins and Saito 2001). If this association between educational status and health persists, it might lead to further declines in prevalence of functional limitations and disabilities in the future and thereby counterbalance the population ageing (Batljan et al. 2009; Freedman and Martin 1999). As far as we know, few studies have identified causes besides those mentioned here. Understanding such causal factors may be important in the planning of future health care needs and for future prevention of disability.

\footnotetext{
Acknowledgments We are grateful for funding from the Faculty of Medicine, University of Oslo. We also thank Inger Texmon for help with the life tables, Tron Anders Moger for comments on the statistical analysis and seminar participants at the University of Oslo for comments and suggestions. We also thank Statistics Norway and the Norwegian Social Science Data Services (NSD) for providing us with the data. In a letter dated 30 September 2008, the NSD gave permission for us to use the data and made it available in anonymous form. We also collected data from the regional database of the NSD. Statistics Norway originally collected and organized the data. Neither Statistics Norway nor the NSD are responsible for the analysis of the data or the interpretations made here. We further thank the journals
}

anonymous reviewers for thoughtful comments and the editor both for valuable suggestions and encouraging comments.

Open Access This article is distributed under the terms of the Creative Commons Attribution Noncommercial License which permits any noncommercial use, distribution, and reproduction in any medium, provided the original author(s) and source are credited.

\section{References}

Arber S, Ginn J (1993) Gender and inequalities in health in later life. Sco Sci Med 36:33-46. doi:10.1016/0277-9536(93)90303-L

Barendregt JJ, Bonneux L, Van der Maas PJ (1994) Health expectancy-an indicator for change. J Epidemiol Community Health 48:482-487

Batljan I, Lagergren M, Thorslund M (2009) Population ageing in sweden: the effect of change in educational composition on the future number of older people suffering severe ill-health. Eur J Ageing 6:201-211. doi:10.1007/s10433-009-0120-1

Bowling A (2005) Mode of questionnaire administration can have serious effects on data quality. J Public Health 27:281-291. doi: 10.1093/pubmed/fdi031

Cambois E, Clavel A, Romieu I, Robine J-M (2008) Trends in disability-free life expectancy at age 65 in france: consistent and diverging patterns according to the underlying disability measure. Eur J Ageing 5:287-298. doi:10.1007/s10433-008-0097-1

Christensen K, Doblhammer G, Rau R, Vaupel JW (2009) Ageing populations: the challenges ahead. Lancet 374:1196-1208. doi: 10.1016/S0140-6736(09)61460-4

Crimmins EM, Saito Y (2001) Trends in healthy life expectancy in the united states, 1970-1990: Gender, racial, and educational differences. Soc Sci Med 52:1629-1641

Cutler DM, Lleras-Muney A (2006) Education and health: Evaluating theories and evidence. Working paper 12352. National Bureau of Economic Research, Cambridge

Daatland SO (1997) Welfare policies for older people in transition? Emerging trends and comparative perspectives. Scandinavian Journal of Social Welfare 6:153-161. doi:10.1111/j.1468-2397. 1997.tb00184.x

Doblhammer G, Kytir J (2001) Compression or expansion of morbidity? Trends in healthy-life expectancy in the elderly Austrian population between 1978 and 1998. Soc Sci Med 52: 385-391

Freedman VA, Martin LG (1998) Understanding trends in functional limitations among older Americans. Am J Public Health 88: $1457-1462$

Freedman VA, Martin LG (1999) The role of education in explaining and forecasting trends in functional limitations among older Americans. Demography 36:461-473

Freedman VA, Martin LG, Schoeni RF (2002) Recent trends in disability and functioning among older adults in the united states: A systematic review. J Am Med Associ 288:3137-3146

Freedman VA, Crimmins E, Schoeni RF, Spillman BC, Aykan H, Kramarow E, Land K, Lubitz J, Manton K, Martin LG, Shinberg $\mathrm{D}$, Waidmann $\mathrm{T}$ (2004) Resolving inconsistencies in trends in old-age disability: report from a technical working group. Demography 41:417-441

Freedman VA, Agree EM, Martin LG, Cornman JC (2006) Trends in the use of assistive technology and personal care for late-life disability, 1992-2001. Gerontologist 46:124-127

Fries JF (1980) Aging, natural death, and the compression of morbidity. New Engl J Med 303:130-135 
Gruenberg EM (1977) The failures of success. Milbank Mem Fund Q $55: 3-24$

Hagen TP, Botten G, Waaler HT (2002) Sprekere eldre, lavere utgiftsbehov i eldreomsorgen? [more fit elderly, lower needs for care services?]. Tidsskrift for Velferdsforskning 5:27-40

Herzog AR, Rodgers WL (1988) Interviewing older adults-mode comparison using data from a face-to-face survey and a telephone resurvey. Public Opin Q 52:84-99

Herzog AR, Rodgers WL (1999) Cognitive performance measures in survey research on older adults. In: Schwarz $\mathrm{N}$ et al (eds) Cognition, aging, and self-reports. Psychology Press, Philadelphia, pp 327-339

Herzog AR, Rodgers WL, Kulka RA (1983) Interviewing older adults-a comparison of telephone and face-to-face modalities. Public Opin Q 47:405-418

Katz S, Ford AB, Moskowitz RW, Jackson BA, Jaffe MW (1963) Studies of illness in the aged - the index of adl—a standardized measure of biological and psychosocial function. J Am Med Assoc 185:914-919

Kempen GIJM, Steverink N, Ormel J, Deeg DJH (1996) The assessment of adl among frail elderly in an interview survey: Self-report versus performance-based tests and determinants of discrepancies. J Gerontol Ser B Psychiol Sci Soc Sci 51B:P254 P260

Lawton MP, Brody EM (1969) Assessment of older people-selfmaintaining and instrumental activities of daily living. Gerontologist 9:179-186

Jagger C, Cox B, Le Roy S, EHEMU (2006) Health expectancy calculation by the sullivan method, 3rd edn. Ehmu Technical Report. September 2006

Manton KG (1982) Changing concepts of morbidity and mortality in the elderly population. Milbank Mem Fund Q Health Soc 60:183-244

Mathers CD, Robine J-M (1997) How good is sullivan's method for monitoring changes in population health expectancies. J Epidemiol Community Health 51:80-86

Oeppen J, Vaupel JW (2002) Demography-broken limits to life expectancy. Science 296:1029-1031. doi:10.1126/science.106 9675

Ostir GV, Carlson JE, Black SA, Rudkin L, Goodwin JS, Markides KS (1999) Disability in older adults 1: prevalence, causes, and consequences. Behav Med 24:147-156

Parker MG, Thorslund M (2007) Health trends in the elderly population: getting better and getting worse. Gerontologist 47:150-158

Parker MG, Ahacic K, Thorslund M (2005) Health changes among swedish oldest old: Prevalence rates from 1992 and 2002 show increasing health problems. J Gerontol 60A:1351-1355

Parker MG, Schön P, Lagergren M, Thorslund M (2008) Functional ability in the elderly Swedish population from 1980 to 2005. Eur J Ageing 5:299-309. doi:10.1007/s10433-008-0096-2

Puts MTE, Deeg DJH, Hoeymans N, Nusselder WJ, Schellevis FG (2008) Changes in the prevalence of chronic disease and the association with disability in the older dutch population between 1987 and 2001. Age Ageing 37:187-193. doi:10.1093/ageing/ afm185

Robine J-M, Michel J-P (2004) Looking forward to a general theory on population aging. J Gerontol Ser A Biol Sci Med Sci 59A:590-597
Rodgers W, Miller B (1997) A comparative analysis of adl questions in surveys of older people. J Gerontol Ser B Psychiol Sci Soc Sci $52 \mathrm{~B}: 21-36$

Rostad B, Deeg DJH, Schei B (2009) Socioeconomic inequalities in health in older women. Eur J Ageing 6:39-47. doi:10.1007/ s10433-008-0104-6

Sagardui-Villamor J, Guallar-Castillón P, García-Ferruelo M, Banegas JR, Rodríguez-Artalejo F (2005) Trends in disability and disability-free life expectancy among elderly people in spain: 1986-1999. J Gerontol Ser A Biol Sci Med Sci 60A:1028-1034

Schoeni RF, Freedman VA, Wallace RB (2001) Persistent, consistent, widespread, and robust? Another look at recent trends in old-age disability. J Gerontol Ser B Psychiol Sci Soc Sci 56B:S206-S218

Schoeni RF, Liang J, Bennett J, Sugisawa H, Fukaya T, Kobayashi E (2006) Trends in old-age functioning and disability in Japan, 1993-2002. Population Studies 60:39-53. doi:10.1080/00324 720500462280

Statistics Norway (2010) Users of home care and institutional care services by age and service type (2007-2009). http://statbank. ssb.no/. Accessed 09 Aug 2010

Sulander TT, Rahkonen OJ, Uutela AK (2003) Functional ability in the elderly Finnish population: time period differences and associations, 1985-99. Scand J Public Health 31:100-106. doi: 10.1080/14034940210133933

Sullivan DF (1971) Single index of mortality and morbidity. Health Serv Rep 86:347-354

The human life-table database (2010) The Max Planck Institute for Demographic Research (MPIDR) in Rostock, Germany, the Department of Demography at the University of California at Berkeley, USA, and the Institut national d'études démographiques (INED), Paris, France. http://www.lifetable.de. Accessed 19 Aug 2010

Thomsen I, Kleven Ø, Wang JH, Zhang L-C (2006) Coping with decreasing response rates in statistics norway. Recommended practice for reducing the effect of nonresponse. Statistics Norway, Oslo/Kongsvinger

van Oort FVA, van Lenthe FJ, Mackenbach JP (2005) Material, psychosocial, and behavioural factors in the explanation of educational inequalities in mortality in the netherlands. J Epidemiol Community Health 59:214-220

Van Oyen H, Cox B, Demarest S, Deboosere P, Lorant V (2008) Trends in health expectancy indicators in the older adult population in Belgium between 1997 and 2004. 146 5:137. doi: 10.1007/s10433-008-0082-8

Verbrugge LM (1985) Gender and health: an update on hypotheses and evidence. J Health Soc Behav 26:156-182

Verbrugge LM, Jette AM (1994) The disablement process. Sco Sci Med 38:1-14

Waaler HM (2005) Pleiebehov blant mottakere av kommunale omsorgstjenester [degree of disability among old people receiving care]. Tidsskr Nor Legeforen 125:1012-1014

Wolf DA, Hunt K, Knickman J (2005) Perspectives on the recent decline in disability at older ages. Milbank Q 83:365-395

Zimmer Z, Martin LG, Chang M-C (2002) Changes in functional limitation and survival among older taiwanese, 1993, 1996, and 1999. Population Studies 56:265-276. doi:10.1080/003247202 15931 